\title{
$p$-Nitrophenol, phenol and aniline sorption by organo-clays
}

\author{
Chun Han Ko ${ }^{a}$, Chihhao Fan ${ }^{\mathrm{b}}$, Po Neng Chiang ${ }^{\mathrm{c}}$, \\ Ming Kuang Wang ${ }^{c}, *$, Kuo Chuan Lin $^{\mathrm{d}}$ \\ a School of Forestry and Resource Conservation, National Taiwan University, Taipei 106, Taiwan \\ ${ }^{\mathrm{b}}$ Department of Safety, Health and Environmental Engineering, Ming-Chi University of Technology, \\ Taishan, Taipei County 243, Taiwan \\ ${ }^{\mathrm{c}}$ Department of Agricultural Chemistry, National Taiwan University, Taipei 106, Taiwan \\ d Taiwan Forest Research Institute, 53 Nanhai Road, Taipei 100, Taiwan
}

Received 12 October 2006; received in revised form 21 March 2007; accepted 23 March 2007

Available online 30 March 2007

\begin{abstract}
The aims of this study were to make use of organo-clays (i.e., Cloisite-10A, Cloisite-15A, Cloisite-30B and Cloisite-93A), to remove $p$ nitrophenol, phenol and aniline of organic pollutants. The organo-clays were characterized by X-ray diffraction (XRD). Sorption isotherm, kinetic and $\mathrm{pH}$ effect of $p$-nitrophenol, phenol and aniline sorbed by four organo-clays were evaluated. The $d$-spacings ( 001$)$ of the XRD peak of Cloisite10A, Cloisite-15A, Cloisite-30B and Cloisite-93A are 1.98, 2.76, 1.93 and $2.64 \mathrm{~nm}$, respectively. The $d(001)$-spacings of XRD indicated that these $p$-nitropheno, phenol and aniline could penetrate into the interlayer of clays and expand the $d(001)$-spacings. The linear sorption isotherm of constant partition was employed to describe the sorption isotherms of phenols sorbed by organo-clays through hydrophobic-hydrophobic chemical reactions. The parabolic diffusion and power-function of kinetic models were employed to describe properly the kinetic experiments. The rate limiting step of the $p$-nitrophenol sorption reactions on organo-clays were diffusion-controlled processes (i.e., 15A, 30B, 93A) and chemicalcontrolled process for 10A organo-clays. The pre-exponential factor of the $p$-nitrophenol sorbed by four organo-clays showed the trend as follows: $10 \mathrm{~A}>30 \mathrm{~B}>93 \mathrm{~A}>15 \mathrm{~A}$. The efficiency of these organo-clays in removing phenol compounds in water treatments merit further study.
\end{abstract}

(C) 2007 Elsevier B.V. All rights reserved.

Keywords: Arrhenius equation; Aniline; Kinetic models; Organo-clays; Phenol; p-Nitrophenol; Sorption isotherms

\section{Introduction}

Soil is known to function as a chemical as well as a biological filter that lessens the impact of organic chemicals on the environments through various processes [1]. The 2:1 layer silicates are important soil constituents in the preparation of organo-clays for polyphenols sorption. Montmorillonite, with its lower surface charge density, has substitution mostly in the octahedral sheet [2]. Inorganic cations in the clays can be exchanged with organic or inorganic chemicals. Hydrophilic clays can be changed to organophilic clays through organic chemicals [3]. Such modified organo-clays have various applications in paper, petroleum (oil-based drilling fluids for deep wells), catalytic, water treatment [4-6], and several other industries. It can also act as a sorbent for a great variety of organic pollutants, such as

\footnotetext{
* Corresponding author. Tel.: +11 88623366 4808; fax: +11 886223660751. E-mail address: mkwang@ntu.edu.tw (M.K. Wang).
}

chlorophenoxy propionic acids (CPA) [7-12], and some weakly acidic pesticides, which have been detected in surface waters [13-17]. These modified organo-clays have acted as a partition media in the sorption of organic pollutants [18-21].

$p$-Nitrophenol, phenol and aniline are common pollutants found particularly in the effluents from pesticides, pharmaceuticals, petrochemicals and other industries. Owing to their toxicity and reactivity, the presence of phenol compounds in the natural environment has been of great concern. In soil environments, the fate of pesticides is governed by the retention, transformation, and transport processes, and the interaction of these processes. Because of agricultural and industrial contamination of ground water by organic chemicals, increased attention has been paid to those factors influencing the reactivity and mobility of organic compounds through soils. Soils are a heterogeneous mixture of numerous components. Clays in soil environment often possess the ability to sorb organic species. The understanding of the reactivity of simple organic matters on clay surfaces can help prevent groundwater contamination [22-24]. 
The organo-clay, modified by quaternary ammonium salts, often used to remove organic contaminants from water. However, the modified organo-clays were effect by their modifier polarity. These modified organo-clays were selected to act as sorbents for the sorption of $p$-nitrophenol, phenol and aniline of organic pollutants. The objective of this study was to evaluate the capabilities and mechanism of organo-clay for selective removal of organic pollutants from water. The $p$-nitrophenol, phenol, and aniline were used as representative organic pollutants in this research.

\section{Materials and methods}

\subsection{Materials}

The organo-clays, Cloisite-10A, Cloisite-15A, Cloisite-30B and Cloisite-93A, were prepared and supplied by Southern Clay Products, County of Gonzales, TX, USA. The Cloisite10A, Cloisite-15A, Cloisite-30B and Cloisite-93A were the SWy-1 montmorillonite modified by 2MBHT (dimethylbenzyl-hydrogenated-tallow, quaternary ammonium), 2M2HT (dimethyl-dehydrogenated-tallow, quaternary ammonium), MT2EtOT (methyl-bis-2-hydroxyethyl-tallow, quaternary ammonium), and M2HT (methyl-dehydrogenated-tallow, quaternary ammonium), respectively (Fig. 1). The modifier concentrations and specific gravity were 125, 95, 90 and $90 \mathrm{cmol} \mathrm{kg}^{-1}$, and $1.90,1.77,1.98$ and $1.88 \mathrm{~g} \mathrm{~mL}^{-1}$, respectively. The hydrogenated tallow was mixed of $\sim 65 \%$ of $\mathrm{C} 18$, $\sim 30 \%$ of $\mathrm{C} 16$ and $\sim 5 \%$ of $\mathrm{C} 14$. These data were adapted from commercial information of Southern Clay Products. The SWy-1 montmorillonite (CEC of $764 \mathrm{cmol} \mathrm{kg}^{-1}$, surface area of $31.82 \mathrm{~m}^{2} \mathrm{~g}^{-1}$ ) (Crook County, Wyoming, USA) was the clay mineral used to prepare organo-clay complexes [25]. The size of these clays used for all experiments were less than $2 \mu \mathrm{m}$. The $p$-nitrophenol, phenol and aniline of analytical grade were obtained from Sigma Company, USA.

\subsection{Physical and chemical properties of p-nitrophenol, phenol and aniline}

$p$-nitrophenol is a colorless to yellowish solid. The chemical formula of $p$-nitrophenol is $\mathrm{C}_{6} \mathrm{H}_{5} \mathrm{NO}_{3}$ and its molecular weight is 139.11 . The solubility of $p$-nitrophenol is $1.6 \mathrm{~g} 100 \mathrm{~mL}^{-1}$. The distribution constant between octanol and water, $\log K_{\text {ow }}$ is 1.91 . Boiling and melting points, vapor pressure and density of $p$-nitrophenol are $279^{\circ} \mathrm{C}, 60^{\circ} \mathrm{C}, 2.2 \mathrm{mmHg}$ and $1.27 \mathrm{~kg} \mathrm{~L}^{-1}$, respectively. The $\mathrm{LD}_{50}$ of $p$-nitrophenol is $620 \mathrm{mg} \mathrm{kg}^{-1}$. Chemical formula and molecular weight of phenol are $\mathrm{C}_{6} \mathrm{H}_{5} \mathrm{OH}$ and 94.11, respectively [26]. Phenol is a colorless to pink-colored solid or dense liquid. The boiling and melting points and vapor pressure of phenol are 182 and $43^{\circ} \mathrm{C}$, and $3.24 \mathrm{mmHg}$, respectively. The solubility, density and $\log K_{\text {ow }}$ of phenol are 9.3,

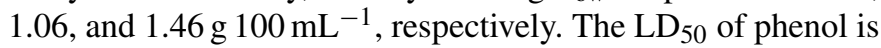
$317 \mathrm{mg} \mathrm{kg}^{-1}$. The chemical formula and molecular weight of aniline are $\mathrm{C}_{6} \mathrm{H}_{5} \mathrm{NH}_{2}$ and 93.13 , respectively. Aniline is a colorless oil. Light radiation causes the browning effect of oil liquid with stun smelling. The solubility, density and $\log K_{\text {ow }}$ of aniline

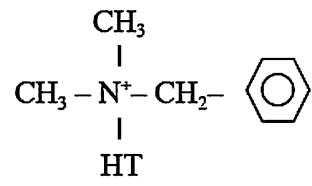

Dimethyl-benzyl-hydrogenerated-tallow, quaternary ammonium (2MBHT) Anion: Chloride

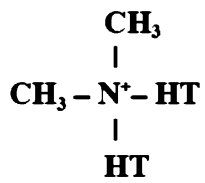

Dimethyl-dehydrogenerated-tallow, quaternary ammonium (2M2HT)

Anion: Chloride

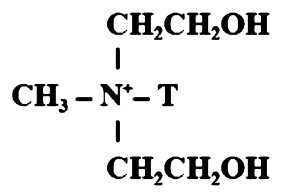

Methyl-bis-2-hydrogxyethyl-tallow, quaternary ammonium (MT2EtOT)

Anion: Chloride

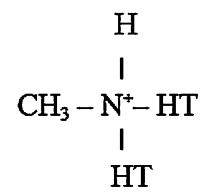

Methyl-dehydrogenated-tallow, quaternary ammonium (M2HT)

Anion: $\mathrm{HSO}_{4}$

Where HT is Hydrogenated Tallow ( $65 \% \mathrm{C} 18, \sim 30 \% \mathrm{C} 16, \sim 5 \% \mathrm{C} 14)$

Fig. 1. Chemical structure of quaternary alkylammonium salts used to prepare organoclays.

are 3.6, 1.02, and $0.90 \mathrm{~g} 100 \mathrm{~mL}^{-1}$, respectively. The $\mathrm{LD}_{50}$ of aniline is $250 \mathrm{mg} \mathrm{kg}^{-1}$. The boiling and melting points, vapor pressure and vapor density of aniline are $184^{\circ} \mathrm{C}$ and $-6^{\circ} \mathrm{C}$, $0.7 \mathrm{mmHg}$ and $3.22 \mathrm{~kg} \mathrm{~L}^{-1}$, respectively [8,10,26-27].

\subsubsection{Methods}

2.2.1.1. Characterization of organo-clays. The organo-clays were prepared as slurries and dropped onto petrographic slides for X-ray diffraction (XRD) [28]. The oriented samples were examined by X-ray diffractometer, using a Rigaku Geigerflex with $\mathrm{Cu} \mathrm{K} \alpha$ radiation with $\mathrm{Ni}$ filter generated at $35 \mathrm{kV}$ and $15 \mathrm{~mA}$. The XRD patterns were recorded in the range of 3 to $50^{\circ} 2 \theta$ at a scanning speed of $1^{\circ} 2 \theta \mathrm{min}^{-1}$. Small amounts of suspension after $p$-nitrophenol, phenol and aniline sorbed by organo-clays were also dropped onto petrographic slides for XRD analyses.

2.2.1.2. p-Nitrophenol, phenol and aniline sorbed by organoclays. For the $p$-nitrophenol, phenol and aniline sorption isotherm studies, $50 \mathrm{mg}$ of organo-clay were placed in $50 \mathrm{~mL}$ centrifuge tube and supplemented with $20 \mathrm{~mL}$ of $0.05,0.075$, $0.1,0.125,0.15,0.175$ and $0.2 \mathrm{mM}$ concentrations of $p$ - 
nitrophenol, phenol and aniline sorption. The suspensions were shaken for $24 \mathrm{~h}$. and centrifuged at $24,000 \times g$ and $25^{\circ} \mathrm{C}$ for $30 \mathrm{~min}$. The phenol concentrations in supernatants were determined in supernatants. For the experiments of sorption isotherms, the constant partition (CP), Langmuir, and Freundlich equations were employed to fit the data of $p$-nitrophenol, phenol and aniline sorptions at the end of the $24 \mathrm{~h}$ reaction time.

Traditionally, the constant partition sorption isotherm indicates that the sorbed-phase concentration $\left(q_{\mathrm{e}}\right)$ is directly proportional to the solution-phase concentration $\left(C_{i}\right)$ :

$q_{\mathrm{e}}=K_{\mathrm{d}} C_{i}$

where $K_{\mathrm{d}}$ is the distribution coefficient ( $\mathrm{L} \mathrm{kg}^{-1}$ organo-clay).

The Langmuir equation is shown in Eq. (2),

$q_{\mathrm{e}}=\frac{K_{\mathrm{L}} B C_{\mathrm{e}}}{1+B C_{\mathrm{e}}}$

where $q_{\mathrm{e}}\left(\mathrm{mmol} \mathrm{kg}^{-1}\right.$ soil) is the equilibrium sorption capacity, $B$ (mmol kg-1 organo-clay) is the maximum monolayer sorption capacity, $C_{\mathrm{e}}\left(\mathrm{mmol} \mathrm{L}^{-1}\right)$ is the equilibrium solute concentration, and $K_{\mathrm{L}}$ is Langmuir affinity constant $\left(\mathrm{L} \mathrm{mmol}^{-1}\right)$.

Another equilibrium-controlled sorption isotherm is the Freundlich sorption isotherm, which can be expressed in the following form:

$q_{\mathrm{e}}=K_{\mathrm{F}} C_{i}^{n}$

where $K_{\mathrm{F}}$ is the Freundlich sorption constant $\left(\mathrm{L} \mathrm{kg}^{-1}\right.$ organoclay) and $n$ is the Freundlich exponent.

\subsection{Effects of kinetic reactions, $p H$ and temperature effects}

Sorption of $0.2 \mathrm{mM}$-nitrophenol at different $\mathrm{pH}$ was prepared and shaken at $0,5,15,30,45,60,120,240,480,720,960$, 1440 and $2880 \mathrm{~min}$ for kinetic sorption studies, using $50 \mathrm{mg}$ of organo-clays and $20 \mathrm{~mL}$ of phenol solutions in $0.01 \mathrm{M} \mathrm{CaCl}_{2}$. The $\mathrm{pH}$ of suspensions were initially adjusted to 4, 7, and 9 with $0.1 \mathrm{M} \mathrm{HCl}$ or $\mathrm{NaOH}$ solutions by $\mathrm{pH}$-stat (Radiometer TIM865) and the constant $\mathrm{pH}$ was maintained for one week. These suspensions were then shaken for $24 \mathrm{~h}$ and centrifuged under the same conditions as the sorption isotherm experiments in triplicates. The equilibrium $\mathrm{pH}$ and $p$-nitrophenol concentrations were then determined in supernatants. The experiment of $p$-nitrophenol sorption by organo-clays was conducted at phenol concentration of $0.2 \mathrm{mM}$ and $\mathrm{pH} 7.0$ at 288, 298, 308 and $318 \mathrm{~K}$. The suspension was made by mixing $50 \mathrm{mg}$ of organo-clays with $25 \mathrm{~mL}$ of $p$-nitrophenol, with $\mathrm{pH}$ adjusted to 7.0 using $\mathrm{HCl}$ or $\mathrm{NaOH}$ solutions by $\mathrm{pH}$-stat and equilibrated at 288, 298, 308 and $318 \mathrm{~K}$ overnight.

The Arrhenius equation was employed to calculate the activation energy $\left(E_{\mathrm{a}}\right)$ and the pre-exponential factor [29]:

$K=A \mathrm{e}^{-E_{\mathrm{a}} / R T}$

where $k$ is the rate coefficient, $A$ is the pre-exponential factor (frequency factor), $E_{\mathrm{a}}$ is the Arrhenius activation energy, $R$ is the universal gas constant, and $T$ is the absolute temperature.
The amounts of $p$-nitrophenol sorption were calculated from the difference between the initial and equilibrium phenol concentrations in sorption isotherm studies. Triplicate kinetic runs were carried out for each treatment. Sorption data were fitted by the kinetic models, including zero-order, first-order, and secondorder equations as well as empirical models including parabolic diffusion, power-function, and Elovich equations. These six selected models were the differential form of the general-rate equation [30].

\subsection{Chemical analyses}

The $p$-nitrophenol, phenol and aniline concentrations in supernatants (i.e., passed through $0.45 \mu \mathrm{m}$ Millipore filter) were determined by UV spectroscopy at $317 \mathrm{~nm}$ for $p$-nitrophenol, $210 \mathrm{~nm}$ for phenol, and $230 \mathrm{~nm}$ for aniline [14,15,31,32]. A blank sample $\left(50 \mathrm{mg}\right.$ of sample with $5 \mathrm{~mL}$ of $0.01 \mathrm{M} \mathrm{CaCl}_{2}$ ) was used for background correction.

\subsection{Statistical analysis}

The linear forms of different kinetic equations were applied to the sorption and kinetic data and their goodness of fit was evaluated based on the $R^{2}$, level of significance ( $p$-value), and standard error (S.E.). The SAS version 8.0 was employed for statistical analysis. Statistical significance was defined as $p=0.05$.

\section{Results and discussion}

The $d$-spacings $\left(\begin{array}{lll}0 & 0 & 1\end{array}\right)$ of the XRD peak of Cloisite10A, Cloisite-15A, Cloisite-30B and Cloisite-93A from our observations are $1.98,2.76,1.93$ and $2.64 \mathrm{~nm}$, respectively (Fig. 2). Zhang et al. [33] reported that sorption of quaternary amines on clays involved at least three types of reactions, viz. a cation-exchange reaction, sorption of ion pairs and tail-tail interactions. The polarity of three organic sorbates showed following trend: phenol $>$ aniline $>p$-nitrophenol. The hydrophobicity of four organo-clays showed the trend as follows: $15 \mathrm{~A}>93 \mathrm{~A}>10 \mathrm{~A}>30 \mathrm{~B}$. Because the modifier of the Closite-10A contained aromatic functional group, it would be shown higher hydrophobic properties than others.

\subsection{X-ray analyses of p-nitrophenol, phenol and aniline sorbed by organo-clays}

The $d\left(\begin{array}{ll}0 & 0\end{array}\right)$-spacings of $p$-nitrophenol, phenol and aniline sorbed by Cloisite-10A expanded to or remained at 1.81 , 1.98 and $2.22 \mathrm{~nm}$, respectively (Fig. 2). On the other hand, $p$-nitrophenol, phenol and aniline sorbed by Cloisite-15A, $d\left(\begin{array}{l}0 \\ 0\end{array}\right.$ 1)-spacings expanded to 2.85, 2.89 and $2.95 \mathrm{~nm}$; Cloisite30B samples expanded to or remained at $1.93,1.95$ and $1.98 \mathrm{~nm}$, and Cloisite-93A samples expanded to $2.75,2.76$, and $2.77 \mathrm{~nm}$, respectively. These results indicate that Cloisite-15A- and Cloisite-93A-sorbed $p$-nitrophenol, phenol and aniline expand the $d\left(\begin{array}{lll}0 & 0 & 1\end{array}\right)$-spacings. Thus, these $p$-nitrophenol and phenol and aniline can penetrate into the interlayer of clays. The Cloisite10A-sorbed $p$-nitrophenol and phenol, and Cloisite-30B-sorbed 

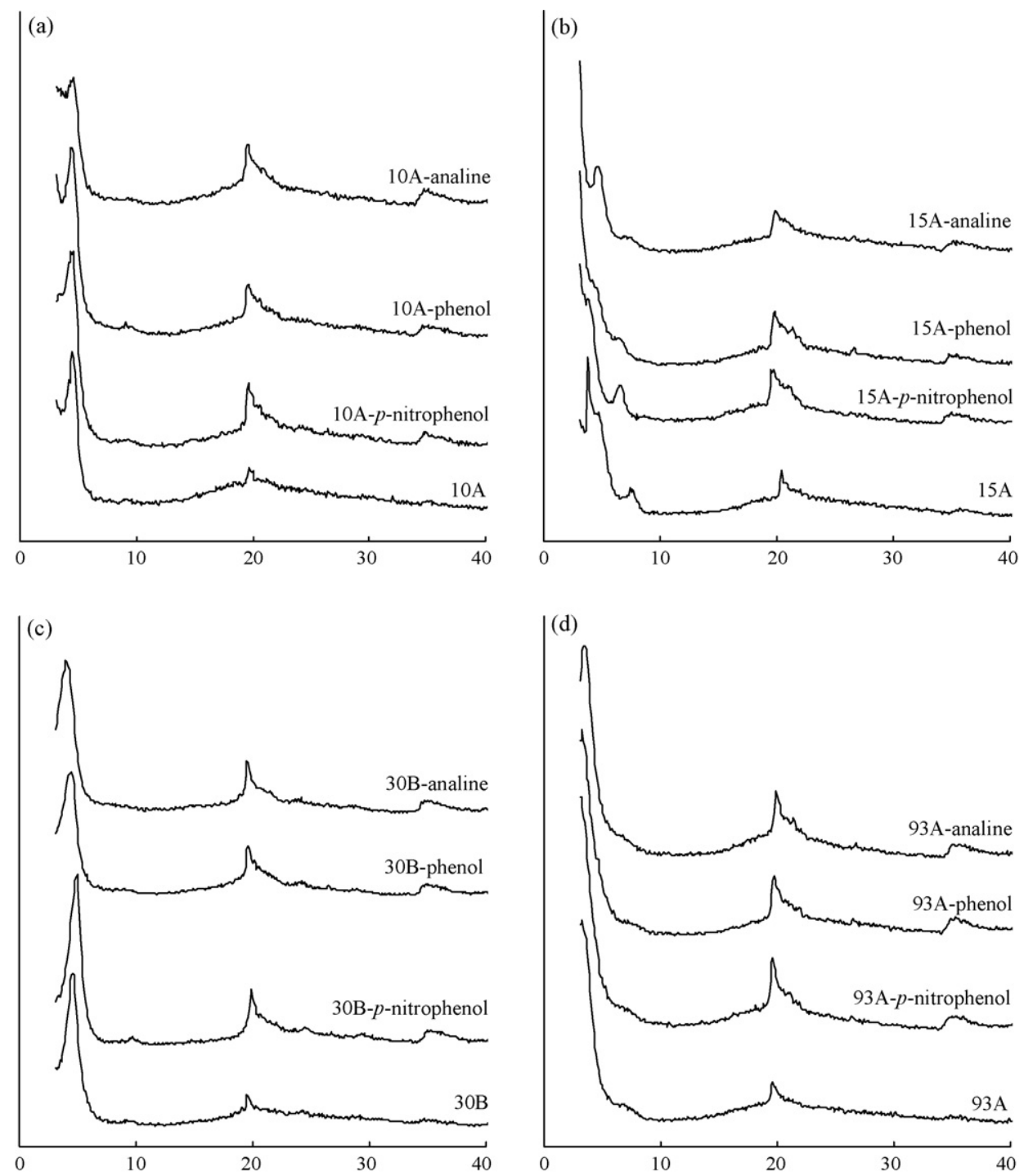

Fig. 2. X-ray diffraction patterns of (a) 10A, 10A-p-nitrophenol, 10A-phenol, and 10A-analine, (b) 15A, 15A-p-nitrophenol, 15A-phenol, and 15A-analine, (c) 30B, 30B-p-nitrophenol, 30B-phenol, and 30B-analine and (d) 93A, 93A-p-nitrophenol, 93A-phenol, and 93A-analine.

$p$-nitrophenol and aniline were the same $d(001)$-spacings as original organo-clays, indicating that no $p$-nitrophenol penetrated into interlayers of clays. The Cloisite-10A-sorbed aniline and Cloisite-30B-sorbed phenols expand their $d\left(\begin{array}{lll}0 & 0 & 1\end{array}\right)$-spacings.

\subsection{Sorption isotherms of p-nitrophenol, phenol and aniline by organo-clays}

Sorption isotherms of $p$-nitrophenol, phenol and aniline sorbed by organo-clays revealed that the data fit well with linear, Langmuir and Freundlich sorption isotherm equations.

The $K_{\mathrm{d}}$ values of $p$-nitrophenol, phenol and aniline sorbed by organo-clays range from 2.49 to $34.39 \mathrm{~L} \mathrm{~kg}^{-1}$ (Table 1). $R^{2}$ range from 0.57 to 0.99 with linear sorption isotherm. The constant determination values $\left(R^{2}\right)$ of phenol sorbed by organoclays are higher than those of $p$-nitrophenol and aniline sorbed by organo-clays. There are some unknown reasons that aniline sorbed by $30 \mathrm{~B}$ organo-clay showed the lowest $R^{2}$ (Table 1 ). The maximum monolayer sorption capacity $(B)$ showed higher phenol sorption with Langmuir sorption isotherm than that of $p$-nitrophenol and aniline sorption by organo-clays. The $n$ values of phenol sorbed by organo-clays were greater than those of $p$-nitrophenol and aniline when Freundlich isotherm equation was applied. The $n$ value is an empirical constant in the Freundlich isotherm equation and range from 0.61 to 1.04 of phenol sorption. In general, three phenols sorbed by four types of organo-clays (10A, 15A, 30B, and 93A) show an obvious linear relationship with the Freundlich equation $\left(R^{2}>0.92\right)$ except aniline sorbed by $30 \mathrm{~B}$ organo-clay. The $K_{\mathrm{L}}$ values of phenol compounds sorbed by $10 \mathrm{~A}$ and $15 \mathrm{~A}$ organo-clays show the following trend: $p$-nitrophenol $>$ phenol $>$ aniline with Langmuir sorption isotherm. However, three phenol compounds sorbed by $30 \mathrm{~B}$ and $93 \mathrm{~A}$ show the reverse tendency. It is related to the polarity and solubility of $p$-nitrophenol $\left(-\mathrm{NO}_{3}, 1.6 \mathrm{~g}\right.$ $\left.100 \mathrm{~mL}^{-1}\right)$, phenol $\left(-\mathrm{OH}, 9.3 \mathrm{~g} 100 \mathrm{~mL}^{-1}\right)$ and aniline $\left(-\mathrm{NH}_{2}\right.$,

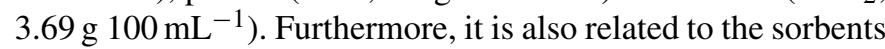
of organo-clays of Cloisite-10A, Cloisite-15A, Cloisite-30B and Cloisite-93A, which were modified by 2MBHT, 2M2HT, 
Table 1

Linear, Langmuir and Freundlich sorption isotherm parameters of $p$-nitrophenol, phenol, and aniline sorption by organo-clays

\begin{tabular}{|c|c|c|c|c|c|c|c|c|}
\hline \multirow[t]{2}{*}{ Clays } & \multicolumn{2}{|c|}{ Linear sorption isotherm } & \multicolumn{3}{|c|}{ Langmuir sorption isotherm } & \multicolumn{3}{|c|}{ Freundlich sorption isotherm } \\
\hline & $\overline{K_{\mathrm{d}}\left(\mathrm{L} \mathrm{kg}^{-1}\right)}$ & $R^{2}$ & $\overline{K_{\mathrm{L}}\left(\mathrm{L} \mathrm{mmol}^{-1}\right)}$ & $B\left(\mathrm{mmol} \mathrm{kg}^{-1}\right)$ & $R^{2}$ & $K_{\mathrm{F}}\left(\mathrm{L} \mathrm{kg}^{-1}\right)$ & $n$ & $R^{2}$ \\
\hline \multicolumn{9}{|c|}{ p-Nitrophenol } \\
\hline $10 \mathrm{~A}$ & 13.5 & 0.91 & 0.45 & 156 & 0.98 & 46.3 & 0.479 & 0.99 \\
\hline $15 \mathrm{~A}$ & 13.5 & 0.91 & 0.87 & 343 & 0.98 & 141.0 & 0.393 & 0.96 \\
\hline 30B & 9.02 & 0.90 & 0.29 & 121 & 0.99 & 28.6 & 0.524 & 0.99 \\
\hline $93 \mathrm{~A}$ & 7.73 & 0.81 & 0.41 & 104 & 0.99 & 28.1 & 0.491 & 0.95 \\
\hline \multicolumn{9}{|l|}{ Phenol } \\
\hline $10 \mathrm{~A}$ & 2618 & 0.99 & 0.05 & 50708 & 0.99 & 3064 & 1.04 & 0.99 \\
\hline $15 \mathrm{~A}$ & 34.39 & 0.98 & 0.72 & 96.04 & 0.99 & 39.12 & 0.68 & 0.99 \\
\hline 30B & 3.85 & 0.97 & 0.002 & 2001 & 0.96 & 4.31 & 0.86 & 0.97 \\
\hline $93 \mathrm{~A}$ & 19.27 & 0.88 & 1.40 & 43.45 & 0.92 & 24.20 & 0.61 & 0.92 \\
\hline \multicolumn{9}{|l|}{ Aniline } \\
\hline $10 \mathrm{~A}$ & 3.79 & 0.93 & 0.002 & 2005 & 0.93 & 4.17 & 0.84 & 0.93 \\
\hline $15 \mathrm{~A}$ & 12.82 & 0.97 & 0.003 & 3701 & 0.94 & 15.34 & 0.68 & 0.99 \\
\hline $30 \mathrm{~B}$ & 2.49 & 0.57 & 4.16 & 5.385 & 0.91 & 4.12 & 0.42 & 0.78 \\
\hline $93 \mathrm{~A}$ & 2.57 & 0.90 & 27.67 & 4.506 & 0.78 & 4.64 & 0.28 & 0.93 \\
\hline
\end{tabular}

${ }^{\mathrm{a}} K_{\mathrm{d}}$ : distribution coefficient; $K_{\mathrm{L}}$ : Langmuir affinity constant; $B$ : maximum monolayer sorption capacity; $K_{\mathrm{F}}$ : Freundlich sorption constant; $n$ : Freundlich exponent.

MT2EtOT, and M2HT, respectively. The hexadecyltrimethylammonium (HDTMA) molecules appear to combine to form an aggregate and reduce the surface area, and charge reversal occurs at more than $100 \%$ CEC of HDTMA [12,32], thus reducing the number of accessible sites [34,35]. Ghosh and Schnitzer [36], and Schnitzer [37] noted that the three parameters controlling the molecular characteristics of organics are the concentration of organic materials, $\mathrm{pH}$ of the system, and ionic strength of the medium.

The Cloisite-15A- and Cloisite-93A-sorbed $p$-nitrophenol, phenol and aniline expand the $d(001)$-spacings. Thus, these phenol compounds can penetrate into the interlayer of clays. The Cloisite-10A-sorbed $p$-nitrophenol and phenol, and Cloisite-30B-sorbed $p$-nitrophenol and aniline had the same $d(001)$-spacings as original organo-clays, indicating that no $p$-nitrophenol has penetrated into interlayers of clays. The Cloisite-10A-sorbed aniline and Cloisite-30B-sorbed phenols also expand their $d(001)$-spacings. The $p$-nitrophenol sorbed by organo-clay showed that the Cloisite-15A had the highest maximum monolayer sorption capacity, suggesting the $p$-nitrophenol sorbed on Cloisite-15A by nonionic interaction. The modifier of Cloisite-15A was more hydrophobic than other organo-clay, thus, the $p$-nitrophenol could easily interacted with Cloisite-15A by non-polar interaction. Boyd et al. [10] reported that $p$-nitrophenol should have been completely nonionic $\left(\log K_{\mathrm{Ow}}=1.91\right)$ hydrophobic, it was sorbed strongly by the organo-clay complexes. The maximum monolayer sorption capacity of phenol sorbed on Cloisite-10A and -30B was 528-1167 and 21-46-folds higher than that on Closite-15A and $-93 \mathrm{~A}$, respectively. The dramatically difference was affected by polarity. The Cloisite-10A and -30B showed more hydrophilic modifiers than others. Meanwhile, the solubility of phenol was higher than $p$-nitrophenol and aniline, thus, phenol could be dissociated easily in the water. Moreover, the $\log K_{\mathrm{ow}}$ of the phenol and aniline are 1.49 and 0.90 , respectively [26,27]. Thus, Westall et al. [26] and Lee et al. [27] suggested that not only most of the sorption was non-coulombic and that hydrophobic or non-polar interaction between alkyl groups on the clays with phenol was possibly the major mechanism, but also dissociated phenol could be sorbed on organo-clay by hydrophilic interaction. The maximum monolayer sorption capacity of aniline sorbed on Cloisite-10A and -15A was 372-445 and 687-821folds higher than that on Closite-30B and -93A, respectively. The polarity and solubility of aniline was between phenol and $p$-nitrophenol. In this experiment, the $\mathrm{pH}$ of suspension was higher than $\mathrm{p} K_{\mathrm{a}}$ of aniline, indicating the lower $\mathrm{H}^{+}$concentration with the lower protonization. The modifiers of Cloisite-10A, $15 \mathrm{~A}$, and $-30 \mathrm{~B}$ contained the same anion (i.e., chloride), but the Cloisite-93A contained lager size of hydrosulfate. Therefore, the aniline tended to partition. Because of the large size of anion, the surface of Cloisite-93A formed steric shielding effect. Thus, the aniline sorption capacity of Cloisite-93A was lower than that of Cloisite-15A. Westall et al. [26] demonstrated that the distribution ratio of hydrophobic ionizable organic compounds, between aqueous and nonaqueous phases is shown to depend on the $\mathrm{pH}$ and ionic strength of the aqueous phase. For aqueous phases with high $\mathrm{pH}$ and ionic strengths, the dominant species of the phenol compounds in the octanol phase were the $-\mathrm{NO}_{3}-$, $-\mathrm{OH}-$, and $\mathrm{NH}_{2}-$ phenolate ions in association with counter ions. Zhu et al. [38] suggested that sorption organic compounds to dual-cation organobentonite is affected by both adsorption and partition, with the relative effect being a function of the types and amounts of incorporated quaternary ammonium cations.

\subsection{Kinetic studies}

The kinetic and empirical equations, including the zero, first-, and second-order rate equations, parabolic diffusion, power-function and Elovich equations were applied to the $p$ nitrophenol sorbed by organo-clays [30]. The goodness-of-fit of the equations to the data was evaluated using the constant of determination $\left(R^{2}\right)$, probability $(p)$, and standard error (S.E.) of 
Table 2

Values of $R^{2}, p$, and standard error (S.E.) for different kinetic models fitted to the $p$-nitrophenol sorption kinetics by organo-clays at $303 \mathrm{~K}$

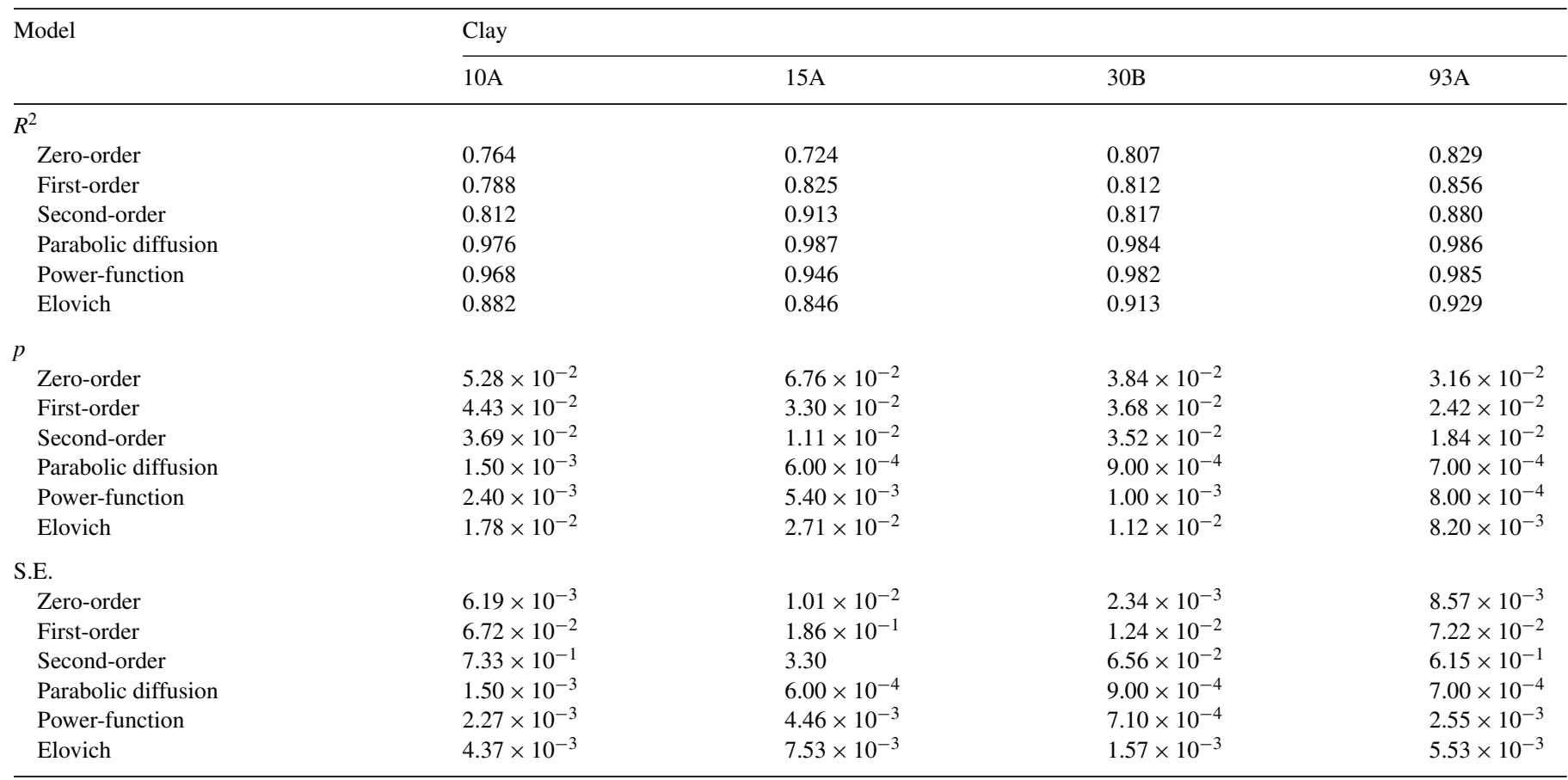

Reaction time (5-60 min)

linear regression analysis. The $R^{2}, p$, and S.E. values of these three parameters obtained by applying different models to the kinetic data obtained in the reactions of $p$-nitrophenol sorbed by four organo-clays are given in Table 2. All six rate equations fit satisfactorily the $p$-nitrophenol sorption data. Among the six models tested, the $R^{2}$ values in parabolic diffusion and powerfunction equations of $p$-nitrophenol sorbed by four organo-clays, and $p$-nitrophenol sorbed by $10 \mathrm{~A}, 15 \mathrm{~A}, 30 \mathrm{~B}$ and $93 \mathrm{~A}$ organoclays fit to the parabolic diffusion equation are all above 0.984 , and those to the power-function are $>0.946$. The $R^{2}$ values of the second-order kinetic model are greater than 0.812 . The $p$ and S.E. values of $p$-nitrophenol sorbed by four organo-clays showed lower parabolic diffusion and power-function of kinetic models than that of the second-order model. According to all these observations, the parabolic diffusion and power-function equations were chosen as the common kinetic models in this study but those two kinetic equations are empirical models. However, in order to determine the rate constants, the second-order kinetic model was recommended. Fig. 3 shows the $p$-nitrophenol sorbed by organoclays and fitted by the second-order kinetic model. The $R^{2}$ values are greater than 0.811 . The kinetic rate of $p$-nitrophenol sorbed by organo-clays with the second- order kinetic model showed the following trend: $15 \mathrm{~A}>10 \mathrm{~A} \approx 93 \mathrm{~A}>30 \mathrm{~B}$ at $\mathrm{pH} 4,7$ and
9 (Table 3). However, the pH had no significant influence on the phenols sorbed by the same organo-clays of hydrophobichydrophobic chemical reactions.

\subsection{Activation energy and pre-exponential factor of p-nitrophenol sorption}

Temperature dependence of the rate constant of $p$-nitrophenol sorption on organo-clays was illustrated in Fig. 4 and Table 4. The rate constant decreases with increasing temperature. This demonstrates that the rate constant of $p$-nitrophenol sorption reactions on organo-clays were of Arrhenius temperature dependence. The activation energy and pre-exponential factor were calculated from the slope and intercept of the plotting of $\ln K$ versus $1 / T$. The activation energies of $p$-nitrophenol sorption data fitted to Arrhenius equation were 84.15, 28.78, 37.05 and $-0.66 \mathrm{~kJ} \mathrm{~mol}^{-1}$ with respect to $10 \mathrm{~A}, 15 \mathrm{~A}, 30 \mathrm{~B}$ and $93 \mathrm{~A}$ organo-clays (Table 5). Low $E_{\mathrm{a}}$ values $\left(<42 \mathrm{~kJ} \mathrm{~mol}^{-1}\right)$ indicate diffusion-controlled processes, whereas high $E_{\mathrm{a}}$ values $\left(>42 \mathrm{~kJ} \mathrm{~mol}^{-1}\right.$ ) (i.e., 10A) indicate chemically-controlled processes [30]. Therefore, the rate limiting step of the $p$-nitrophenol sorption reactions on organo-clays were diffusion-controlled processes (i.e., 15A, 30B, 93A). Diffusion processes, which

Table 3

Second-order rate constants for $p$-nitrophenol sorption by organo-clays

\begin{tabular}{|c|c|c|c|c|}
\hline & \multicolumn{4}{|l|}{ Clay } \\
\hline Rate constant $\left(\mathrm{mM}^{-1} \mathrm{~min}^{-1}\right)$ & $5.9 \times 10^{-2}$ & $4.1 \times 10^{-1}$ & $5.4 \times 10^{-3}$ & $6.4 \times 10^{-2}$ \\
\hline
\end{tabular}




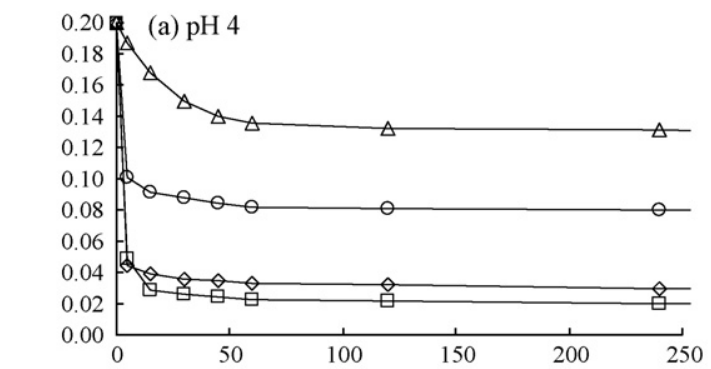

$\diamond 10 \mathrm{~A}$

$\square 15 \mathrm{~A}$

$\triangle 30 \mathrm{~B}$

$\circ 93 \mathrm{~A}$
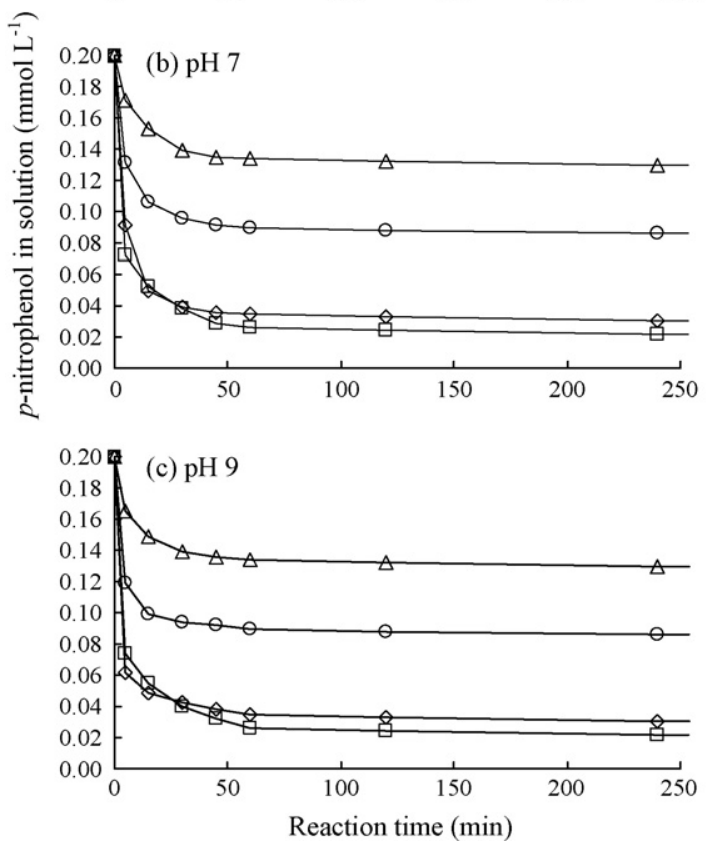

Fig. 3. $\mathrm{pH}$ effects on the kinetics of $p$-nitrophenol sorption on clays. Experiments were conducted with clay concentration, $2.0 \mathrm{~g} \mathrm{~L}^{-1}$; initial $\mathrm{pH} 7.0$; initial concentration of $p$-nitrophenol $0.2 \mathrm{mM}$.

include diffusion of sorbate occluded in micropores (pore diffusion) and along pore-wall surfaces (surface diffusion) and diffusion processes in the bulk of the solid may dominate the kinetics of the overall processes and they are also extremely important in controlling the rates of sorption and desorption of $p$-nitrophenol from surface coordination sites of sorbents [39]. The pre-exponential factor of the $p$-nitrophenol sorbed by four organo-clays showed the trend as follows: $10 \mathrm{~A}>30 \mathrm{~B}>93 \mathrm{~A}>15 \mathrm{~A}$. The lower activation energy and higher pre-exponential factor corresponded to the higher coefficient rate.

Table 4

Second-order rate constants for $p$-nitrophenol sorption by clays at different temperatures

\begin{tabular}{lllll}
\hline Clay & \multicolumn{4}{l}{ Rate constant $\left(\mathrm{mM}^{-1} \mathrm{~min}^{-1}\right)$} \\
\cline { 2 - 5 } & $278^{\mathrm{a}}$ & $288^{\mathrm{a}}$ & $298^{\mathrm{a}}$ & $308^{\mathrm{a}}$ \\
\hline $10 \mathrm{~A}$ & 0.111 & 0.298 & 0.059 & 0.036 \\
$15 \mathrm{~A}$ & 0.687 & 0.458 & 0.418 & 0.199 \\
30B & 0.007 & 0.029 & 0.005 & 0.011 \\
93A & 0.006 & 0.059 & 0.065 & 0.060 \\
\hline
\end{tabular}

\footnotetext{
a Temperature $(K)$.
}
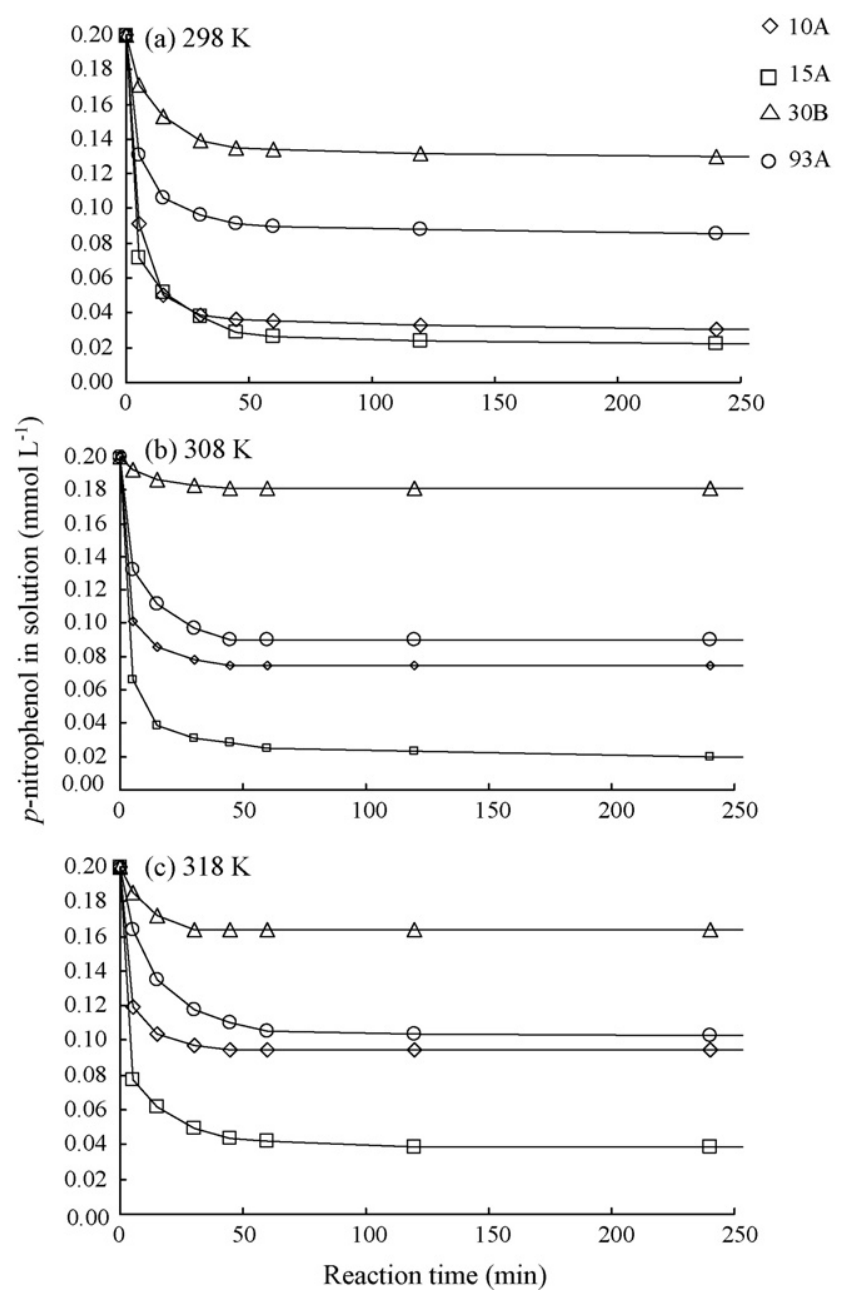

Fig. 4. Temperature effects on the kinetics of $p$-nitrophenol sorption on clays. Experiments were conducted with clay concentration, $2.0 \mathrm{~g} \mathrm{~L}^{-1}$; initial $\mathrm{pH} 7.0$; initial concentration of $p$-nitrophenol $0.2 \mathrm{mM}$.

Table 5

Activation energy and pre-exponantial factor of $p$-nitrophenol sorption on the organo-clays

\begin{tabular}{lll}
\hline Clay & $\begin{array}{l}\text { Activation energy } \\
\left(\mathrm{kJ} \mathrm{mol}^{-1}\right)\end{array}$ & $\begin{array}{l}\text { Pre-exponantial factor } \\
\left(\mathrm{M}^{-1} \mathrm{~h}^{-1}\right)\end{array}$ \\
\hline $10 \mathrm{~A}$ & 84.15 & $3.72 \times 10^{10}$ \\
$15 \mathrm{~A}$ & 28.78 & 3.85 \\
$30 \mathrm{~B}$ & 37.05 & $1.60 \times 10^{8}$ \\
$93 \mathrm{~A}$ & -0.66 & 12.6 \\
\hline
\end{tabular}

\section{Conclusions}

Sorption of phenol compounds by organo-clays was affected by the concentration, solubility and $\log K_{\text {ow }}$ of sorbates, temperature, kinetic reaction time, and steric contour of organics. The suspension $\mathrm{pH}$ had no significant influence the sorption of phenol compounds by organo-clays through hydrophobic-hydrophobic chemical reaction. The rate limiting step of the $p$-nitrophenol sorption reactions on organo-clays were diffusion-controlled processes (i.e., 15A, 30B, 93A), however, $p$-nitrophenol sorbed by 10A showed the activation energy of $84.15 \mathrm{~kJ} \mathrm{~mol}^{-1}$, indicating chemically-controlled processes. 
The efficiency of these organo-clays in removing phenol compounds in water treatments will be further explored in future studies. Development of innovative organo-nanopaticles of layered silicated and silica nanocomposites with large surface area merits more in-depth research.

\section{Acknowledgments}

This study was supported financially by the National Science Council, Taiwan, Republic of China, under projects NSC 912313-B-002-361, 92-2313-B-002-035 and 93-2313-B-002-008.

\section{References}

[1] D.M. Linn, T.H. Carski, M.L. Brusseau, F.H. Chang, Sorption and degradation of pesticides and organic chemicals soils, Soil Sci. Soc. (1993) 260.

[2] G.A. Borchardt, in: J.B. Dixon, S.B. Weed (Eds.), Minerals in soil environments, Smectites, Soil Sci. Soc. (1989) 675-727.

[3] R.F. Giese, in: C.J. van Oss, S. Yariv, H. Cross (Eds.), Organophilicity and Hydrophobicity of Organo-clays, Marcel Dekker, New York, 2002, pp. 175-192.

[4] S.K. Dentel, A.I. Jamrah, D.L. Sparks, Water Res. 32 (1998) 3689-3697.

[5] S.K. Dentel, J.Y. Bottero, K. Khatib, H. Demougeot, J.P. Duguet, C. Anselme, Water Res. 29 (1995) 1273-1280.

[6] H.T. Zhao, G.F. Vance, Water Res. 32 (1998) 3710-3716.

[7] B.K.G. Theng (Ed.), The Chemistry of Clay-Organic Complexes, Adam Hilger, London, 1974.

[8] M.M. Mortland, S. Shaobai, S.A. Boyd, Clays Clay Miner. 34 (1986) $581-585$.

[9] S.A. Boyd, M.M. Mortland, C.T. Chou, Soil Sci. Soc. Am. J. 52 (1988) 652-657.

[10] S.A. Boyd, S. Shaobai, J.F. Lee, M.M. Mortland, Clays Clay Miner. 36 (1988) 125-135.

[11] G.H. Sheng, C.T. Johnston, B.J. Teppen, S.A. Boyd, Clays Clay Miner. 50 (2002) 25-34.

[12] C.J. Liao, C.P. Chen, M.K. Wang, P.N. Chiang, C.W. Pai, Environ. Toxicol. 21 (2006) 71-79.

[13] R.D. Wauchope, J. Environ. Qual. 7 (1978) 459-472.

[14] M.C. Hermosin, J. Cornejo, Chemosphere 24 (1992) 1493-1503.

[15] M.C. Hermosin, J. Cornejo, J. Environ. Qual. 22 (1993) 325-331.

[16] M.J. Carrizosa, M.C. Hermosin, W.C. Koskinen, J. Cornejo, Soil Sci. Soc. Am. J. 67 (2003) 511-517.
[17] P. Patnaik, J.N. Khoury, Water Res. 38 (2004) 206-210.

[18] M.M. Mortland, Adv. Agron. 22 (1970) 75-117.

[19] W.F. Janes, S.A. Boyd, Soil Sci. Soc. Am. J. 55 (1991) 43-48.

[20] J.M. Chern, Y.W. Chien, Water Res. 36 (2002) 647-655.

[21] S. Yariv, Organo-clay complexes and interactions, in: S. Yariv, H. Cross (Eds.), Introduction to Organo-Clay Complexes and Interactions, Marcel Dekker, New York, 2002, pp. 39-112.

[22] B.L. Sawhney, K. Brown (Eds.), Reactions and movement of organic chemicals in soils, Soil Sci. Soc. Am. (1989).

[23] H.H. Cheng (Ed.), Pesticides in the soil environment: processes impacts, and modeling, Soil Sci. Soc. Am. (1990).

[24] J.H. Park, D. Kay, X. Zhao, S.A. Boyd, T.C. Voice, J. Environ. Qual. 30 (2001) 1523-1527.

[25] H. van Olphen, J.J. Fripiat (Eds.), Data Handbook for Clay Minerals and other Non-Metallic Minerals, Pergamon Press, Oxford, 1979, p. p. 346.

[26] J.C. Westall, C. Leuenberger, R.P. Schwarzenbach, Environ. Sci. Technol. 19 (1985) 193-198.

[27] M.R. Lee, Y.C. Yeh, W.S. Hsiang, B.H. Hwang, J. Chromatogr. A 806 (1998) 317-324.

[28] M.L. Jackson (Ed.), Soil Chemical Analysis, 1979, Published by author, Madison, WI.

[29] J.W. Moore, R.G. Pearson (Eds.), Kinetics and Mechanisms, third ed., John Wiely \& Sons, New York, 1981.

[30] D.L. Sparks (Ed.), Kinetics and Mechanisms of Chemical Processes, Academic Press, New York, 1989.

[31] E.R. Bogus, T.L. Watschke, R.O. Mumma, J. Agri. Food Chem. 38 (1990) $142-144$.

[32] Y.H. Hsu, M.K. Wang, C.W. Pai, Y.S. Wang, Appl. Clay Sci. 16 (2000) $147-159$.

[33] Z.Z. Zhang, D.L. Spark, N.C. Scrlvner, Environ. Sci. Technol. 27 (1993) $1625-1631$

[34] M. Schnitrzer, in: P.M. Huang, M. Schnitrzer (Eds.), Interactions of soil minerals with natural organics and microbes. Binding of humic substances by soil mineral colloids, Soil Sci. Soc. Am. (1986) 77-102.

[35] P. Chandar, P. Somasundaran, N.J. Turro, J. Coll. Interf. Sci. 117 (1987) $31-46$.

[36] K. Ghosh, M. Schnitzer, Soil Sci. Soc. 129 (1980) 266-276.

[37] M. Schnitzer, Environmental impact of soil component interactions, in: P.M. Huang, J. Berthelin, J.M. Bollag, W.B. McGill, A.L. Page (Eds.), Organic-Inorganic Interactions in Soils and their Effects on Soil Quality, Lewis Publishers, Boca Raton, FL, 1995, pp. 3-19.

[38] L. Zhu, B. Chen, X. Shen, Environ. Sci. Technol. 34 (2000) 468-475

[39] C.C. Fuller, J.A. Davis, G.A. Waychunas, Geochim. Cosmochim. Acta 57 (1993) 2271-2282. 